\title{
ASPECTOS ECOLÓGICOS DA TRIPANOSSOMíASE AMERICANA. VIII - DOMICILIAÇÃO DE PANSTRONGYLUS MEGISTUS E SUA PRESENÇA EXTRADOMICILIAR *
}

\author{
Oswaldo Paulo Forattini ** \\ Octávio Alves Ferreira**** \\ Eduardo Olavo da Rocha e Silva *** \\ Ernesto Xavier Rabello**
}

\begin{tabular}{r|r}
- \\
RSPU-B/340
\end{tabular}

Forattini, O. P. et al. Aspectos ecológicos da Tripanossomiase americana. VIII - Domiciliação de Panstrongylus megistus e sua presença extradomiciliar. Rev. Saúde públ., S. Paulo, 11:73-86, 1977.

Resumo: São apresentados os resultados iniciais de observaçōes destinadas a evidenciar a presença de Panstrongylus megistus domiciliado e silvestre em uma mesma localidade. Os resultados sugerem a domiciliacáo desse triatomíneo ao lado de seus hábitos extradomiciliares. Estes estão localmente predominantes como ocos de arvores que servem de abrigos a animais silvestres. A presença desses focos naturais ocorre nas manchas de florestas residuais e a capacidade invasira em relação aos ecótopos naturais evidenciou-se atracés da colonização de galinheiros experimentais instalados nesses locais.

Unitermos: Tripanossomíase americana. Panstrongylus megistus. Triatomineos, domiciliação. Ecologia médica.

\section{N T R O D U C $\mathrm{A} O$}

A acentuada domiciliação do Panstrongylus megistus, que se observa em várias regiōes do Brasil, redundou em sua elevada importância epidemiológica como transmissor regional da tripanossomíase americana. Esse fato é conhecido desde longa data, embora o mesmo não se possa dizer quanto ao encontro desse triatomíneo em condições extradomiciliares. Com efeito, foi somente a partir dos anos sessenta que ocorreram, nesse particular, os achados mais significativos. Revelouse, assim, apreciável variedade de ecótopos naturais, passiveis de serem habitados pelo hemíptero (Barretto ${ }^{3}$ : 1966). Em conseqüência surgiu a questão de se essa espécie seria ou não monotípica. Em outras palavras, tornou-se necessário esclarecer a existência de população com valência ecológica suficiente para invadir as habitações e. consequientemente, domiciliar-se ou se seriam duas ou mais po-

* Realizado com o auxilio financelro parclal da Fundação de Amparo à Pesquisa do Estado de São Paulo (Proc. C. Médicas $72 / 770$ ).

* Do Departamento de Epidemiologia da Faculdade de Saúde Pública da USP - Av. Dr. Arnaldo, 715 - São Paulo, SP - Brasil.

*:*: Da Diretoria de Combate a Vetores da Superintendência de Controle de Endemias (SUCEN) do Estado de São Paulo - Rua Tamandaré, 649 - São Paulọ, SP - Brasil. 
FORATTINI, O. P. et al. - Aspectos ecológicos da Tripanossomiase americana, VIII - Domiciliação de Panstrongylus megistus e sua presença extradomiciliar. Rev. Saúde públ., S. Paulo, 11:73-86, 1977.

pulações com hábitos distintos, sinantrópicos e silvestres. O problema continua em aberto e, a maior ou menor freqüência com que foram registrados os encontros de $P$. megistus em biótopos naturais, tem sido explicada por meio de diversas hipóteses. Há as que admitem a politipia com barreiras naturais de ordem climática $e$ as que aceitam a existência de população monotípica euritopa, atribuindo a escassez dos encontros de ecótopos silvestres ao número limitado de pesquisas levadas a efeito nesse sentido (Aragão", 1961; Pessoa ${ }^{13}$, 1962; Barretto ${ }^{3}$, 1966; Forattini e col. ${ }^{6}, 1970$ e Miles $\left.{ }^{11}, 1976\right)$.

$O$ interesse em conhecer as implicações desse comportamento torna-se óbvio, face às campanhas que foram ou estão sendo encetadas para o controle e possível erradicação desse inseto. Compreende-se que a eficácia dessas medidas estaria forçosamente subordinada, entre outros fatores, à possivel existência de comportamento invasivo com subseqüente domiciliação, a partir de focos extradomiciliares. No Estado de São Paulo, Brasil, o comhate aos triatomíneos pela aplicação de inseticidas nas habitações, levado a efeito pela atual Superintendência de Controle de Endemias (SUCEN), resultou em acentuada queda ou mesmo desaparecimento, em grandes áreas, do Triatoma infestans. Contudo o mesmo não ocorreu com outras espécies, entre elas, o $l$. megistus cuja participação nos resultados das capturas vem acusando sensível aumento (Rocha e Silva et al. ${ }^{14}, 1969$ ). Em que pesem os múltiplos fatores outros que, com o passar do tempo, poderiam influir no melhor rendimento das coletas, o fato é que o comparecimento do triatomíneo tem sido de molde a despertar a atenção. Em termos gerais. o estado atual no território paulista sugere o interesse imediato na realização de pesquisas visando observar o comportamento da, ou das populações desse heróptero.

Por outro lado, é de se assinalar que. em regiões com $P$. megistus francamente domiciliado, já tinham sido registradas a sua persistência e capacidade de reinfestação das casas. Observações levadas a efeito no Estado de Minas Gerais, Brasil, evidenciaram a menor sensibilidade desse "harbeiro" às tentativas de sua erradicação por meio do expurgo domiciliar. Esses dados concordam com os obtidos no Estado de São Paulo em localidade onde, anteriormente à aplicação de inseticidas, o triatomíneo desempenhava papel secundário nos ecótopos artificiais. Tais aspectos vieram sugerir, fortemente, a presença de processo substitutivo das populações domiciliadas de $T$. infestans pelas de $P$. megistus, em decorrência da eliminação daquelas (Freitas ${ }^{10}, 1963$ e Dias ${ }^{\text {t, }}$ 1965, 1968).

No estado atual reconhecem-se dois tipos de comportamento do P. megistus correspondendo a distribuição geográfica mais ou menos estabelecida, ao se tomar como limite linha hipotética que percorra o norte-nordeste do Estado de São Paulo. Ao norte observa-se a ocupação dos biótopos artificiais, com conseqüente domiciliação, ao passo que ao sul, o triatomíneo parece restrito ao ambiente natural (Aragão ${ }^{2}, 1961$ e Forattini ${ }^{7}, 1972$ ). Como se mencionou, a explicação desse fato ainda não foi obtida de maneira satisfatória. Por sua vez, reveste-se de alta importância a resposta a perguntas sobre o que poderá ocorrer após o esvaziamento do correspondente nicho ecológico nas biocenoses artificiais existentes em ambientes domiciliares, e quais seriam as possibilidades de substituição das populações triatomínicas eliminadas (Forattini ${ }^{8}, 1976$ ).

Para a realização de pesquisas visando o esclarecimento dessas questões, o Estado de São Paulo e suas zonas limítrofes, oferecem campo extremamente favorável. $\mathrm{E}$ isso por várias razōes. Em primeiro lugar, como foi mencionado, a sua região norte-nordeste seria de possível transição entre duas hipotéticas populações. Além disso, possui ampla área de ecossistema 
FORATTINI, O. P. et al. - Aspectos ecológicos da Tripanossomíase americana. VIII - Domiciliação de Panstrongylus megistus e sua presença extradomiciliar. Rev. Saúde públ., S. Paulo, 11:73-86, 1977.

natural na Serra do Mar, com a presença de população eminentemente silvestre. Acrescente-se a circunstância de ter sido objeto de campanha intensa e regular de combate aos triatomíneos domiciliados, e que levou à sua redução acentuada ou mesmo eliminação. Finalmente, o fato de grande parte do território paulista encontrar-se atualmente em fase de vigilância, enreịa condições ótimas para as investigaçōes. Face a isso foi programada e executada série de observações cujo relato inicia-se com o presente trabalhc. Neste procura-se descrever quadro básico de distribuição local do $P$. megistus, bem como as rimeiras tentativas de observação de seu comportamento.

\section{Kegião estudada}

A região onde foram levadas a efeito estas observaçōes, compreende quatro localidades do município de Cássia dos Coqueiros, situado no nordeste do Estado de São Paulo e limítrofe com o vizinho Estado de Minas Gerais (Fig. 1). Encontram-se, aproximadamente, entre $21^{\circ} 05^{\prime} \mathrm{e}$ $21^{\circ} 20^{\circ}$ de latitude sul e de $47^{\circ} 05^{\prime}$ a $47^{\circ} 15^{\prime}$ de longitude oeste. A sede municipal dista an redor de $20 \mathrm{~km}$ da vizinha cidade paulista de Cajurú e a cerca da mesma distância em relação à congênere mineira de Monte Santo.

Esta região localiza-se no limite norte da Depressão Paleozóica constituindo-se no que se poderia chamar de prolongamento meridional do Planalto de Franca. Dessa maneira, apresenta-se com topografia semelhante a este, a julgar pelas des. criçōes e estudos existentes (Ab'Sáher ${ }^{1}$. 1975). Assim, em altitude que varia de 700 a pouco mais de 1000 metros, observa-se terreno acentuadamente ondulad, que termina a leste e sudeste por escar. pas altas de arenito-basalto, filiadas ao mesmo sistema das cuestas do nordeste de São Paulo e oeste de Minas Gerais.

$\mathrm{Na}$ divisão ecológica do Estado de São Paulo, esta área inclui-se na sub-região quente da Serra Geral (SGq) de Setzer ${ }^{15}$ (1966), ou então no altiplano de França como subdivisão da sexta região, ou Centro-Norte, de Troppmair ${ }^{16}$ (1975). No primeiro caso, a classificação considera os elementos climáticos e pedológicos, enquanto que, no segundo, leva em conta critérios fenológicos.

Os aspectos do clima fazem com que. de acordo com Setzer ${ }^{1:)}$ (1966), esta área se constitua em bolsão local classificado no tipo Cwb de Koeppen. Por sua vez. no sistema de Monteiro ${ }^{12}$ (1973), incluise na feição climática $V_{c}$ do tipo $A_{2}$. A primeira classificação baseia-se nos dados de pluviosidade e de temperaturas médias, ao passo que a segunda utiliza, como critério, a atuação das massas de ar envolvidas na circulação regional e que se refletem na produção de chuvas. De qualquer maneira, as características climáticas da região são do tipo temperado, com período seco nítido e contrastante com o chuvoso que o sucede pois este apresenta elevados índices de precipitação. Quanto à temperatura, é inferior a $18^{\circ} \mathrm{C}$ e a $22^{\circ} \mathrm{C}$, como média, para o mês mais frio (julho) e mais quente (janeiro), respectivamente.

Tais feições climáticas, caracterizadas pela alternância de épocas nítidas do ano, propiciam os aspectos fenológicos com a predominância de plantas tropófilas. Tanto pela sua situação como pelas peculiaridades supradescritas. esta área pode ser considerada como uma parte da região de transição que caracteriza o altiplano de Franca. Esse aspecto tem sido reconhecido como zona de contato entre paisagens hotânicas distintas como as florestas do planalto paulista e os cerrados do ocidente de Minas Gerais e sul de Goiás. De maneira geral, representa a passagem entre o centro e o sul do Brasil, com tendência para as formações vegetais do centro-oeste (Ab'Sáber ${ }^{1}$ 1975, Troppmair ${ }^{1 \mathrm{ti}}$ 1975). Por outro lado, no que concerne ao objeto destas pesquisas, 


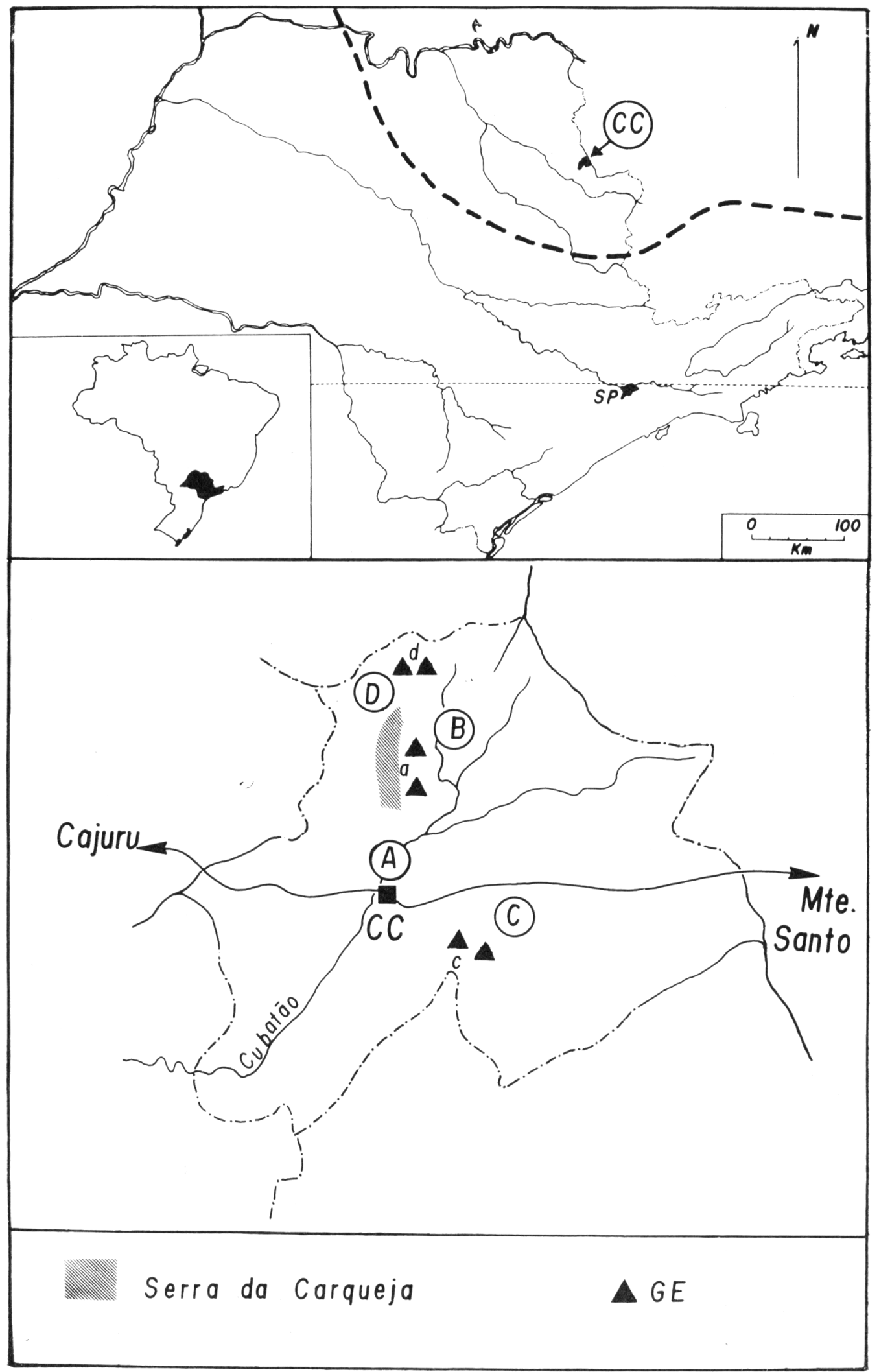

Fig. 1 - Localização das áreas estudadas no municipio de Cássia dos Coquerios (CC). Os galinheiros experimentais (GE) estão indicados, aos pares, pelas letras minúsculas corres. pondentes no texto. A linha interrompida no mapa do Estado de São Paulo indica o limite hipotético das formas de Panstrongylus megistus, correspondendo ao norte as domicliadas e ao sul, as silvestres de acordo com Aragão (1961). 
FORATTINI, O. P. et al. - Aspectos ecológicos da Tripanossomiase americana. VIII - Domiciliação de Panstrongylus megistus e sua presença extradomiciliar. Rev. Sañle públ., S. Paulo, 11:73-86, 1977.

a área estudada situa-se também em hipotética zona limítrofe entre os dois já mencionados tipos de comportamento do l'anstrongylus megistus, ou seja, em concordância com a transição climática que separa aquelas duas regiões do país (Aragão ${ }^{2}$, 1961 ) (Fig. 1).

A vegetação local é representada por campos, cerrados e restos de matas resultantes da destruição da primitiva cobertura natural. $O$ aproveitamento da terra inclui atualmente lavouras variadas com certo predomínio de milho. cana, algodão, arroz e café. Boa parte da área é utilizada para a pecuária de gado bovino leiteiro, contribuindo, para isso, a existência de pastagens naturais. Assim sendo, a paisagem predominante consiste em áreas de cultivo e de pasto pouco extensos, entremeadas por capões de mata de tamanho variável. Os individuos vegetais são representados, com predominância, por árvores de pequeno e médio porte, plantas arbustivas e palmeiras. Nas roças e pastagens observa-se, com freqüência, a presença de espécimens isolados, vivos ou seco, erectos ou derrubados. Em menor número e nas manchas de mata residual de maior extensão, pode-se observar a presença de árvores de elevado porte.

As habitações são construídas, predominantemente, com paredes de tijolos ou de barro, rebocadas. Seu estado de conservação, em geral, é precário e assim oferecem bom abrigo potencial para triatomíneos. Os anexos são freqüentes e numerosos, representados não apenas pelos abrigos de animais domésticos, mas também pelos depósitos de gêneros e implementos agrícolas de toda a espécie, e conhecidos como "paióis", além de coberturas para as fossas ou latrinas.

A escolha desta regjão prendeu-se ao fato de ter sido sede de prolongada e sistemática campanha de controle de triatomíneos, através da aplicação domiciliar de inseticidas (Freitas ${ }^{10}, 1963$ ). Em conseqüência, deu-se o desaparecimento da po- pulação de $T$. infestans que anteriormente infestava as habitações. Restou a de $P$. megistus, cujo comportamento passou a ser ohjeto destes estudos. Para tanto, como já se mencionou, foram escolhidas três localidades. Com isso, pretendeu-se abranger, o mais possível, o aspecto paisagístico regional, com a inclusão de feições mais particularizadas. As características de cada uma são as apresentadas a seguir.

A primeira é a mais extensa e está situada nas vertentes do vale do rio Cubatão, que deságua no rio Pardo. É percorrida também por vários afluentes do primeiro, conhecidos por diversos nomes sendo, os mais conhecidos, aqueles correspondentes aos de rios da Prata, Jacaré e da Delícia. A área selecionada compreende as localidades denominadas de Bairro da Carqueja e Bairro Jacaré. Inclui-se nela os aspectos anteriormente descritos e, de maneira particular, representa zona de maior grau de atividade agricola e de densidade habitacional. Assim sendo, ao lado de terrenos abertos para a agricultura e a pecuária, em número apreciável, observa-se a existência de limitado número de manchas de matas residuais. No seu limite ao norte. encontra-se saliente escarpa de arenito-basalto conhecida como Serra da Carqueja. Tal formação empresta feição acidentada à paisagem e, em seu sopé, pode-se notar o desenvolvimento de vegetação predominantemente de porte médio e arbustivo, embora se encontrem, de maneira esparsa, individuos arbóreos altos. Desse ponto descortina-se panorama que inclui as duas localidades supramencionadas e todo o vale do sistema do rio Cubatão, o que fornece boa idéia geral das características regionais (Figs. 2 e 3).

A segunda é representada pela localidade conhecida como Bairro da Boiada, atravessada por curso d'água que leva o mesmo nome. Caracteriza-se por menor número de casas e de lavouras, se comparada com a interior, mas com maior 
FORATTINI, O. P. et al. - Aspectos ecológlcos da Tripanossomiase americana. VIII - Domiclliacão de Panstrongylu. megistus e sua presenca extradomiclliar. Rer. Saúde públ. S. Paulo, 11:73-86, 1977.

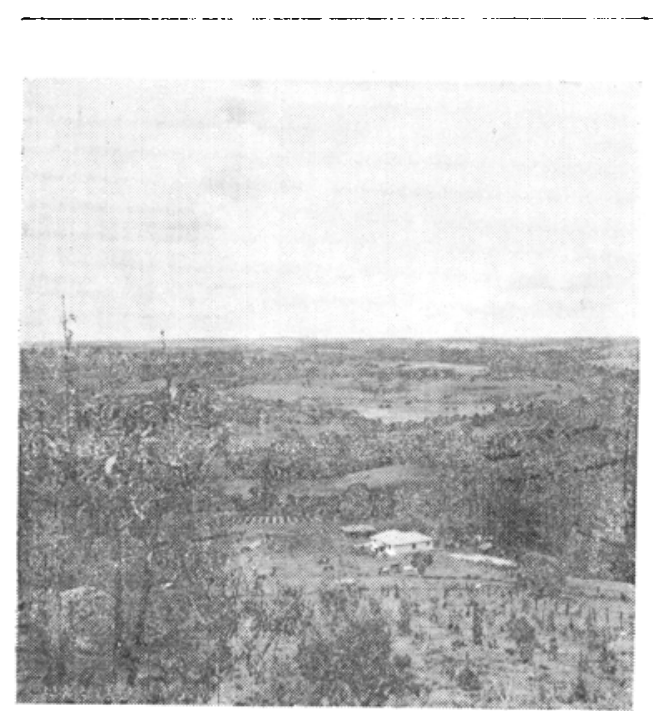

Fig 2 - Aspecto panorâmico dos Bairros da Carqueja e Jacaré, observando-se o terreno utilizado e as manchas de matas residuals.

extensão de matas residuais. Vestas podese observar, com maior freqüência. a presença de árvores mais altas è aspecto mais fechado ao nível do solo (Fig. 4).

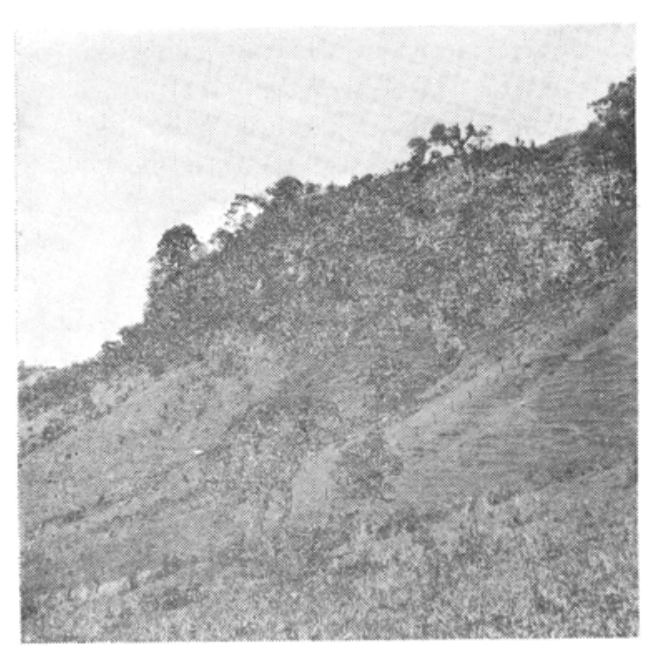

Fug 3 - Aspecto da escarpa de arenito-basalto conheruda localmente como serra da Carqueja. notando-se a vegetarão situada no sopé.
Finalmente. a terceira corresponde à localidade conhecida como Bairro Monte Alto, e caracteriza-se também por menor concentração de habitações. Ao lado disso. apresenta maior abundância de terreno utilizado para o pasto do gado. A regelação residual concentra-se ao longo dos pequenos cursos d’áqua ou em conjuntos isolados cercados pelas pastagens (Fig. 51 .

\section{MATERIAL E MÉTODOS}

$O$ objetivo inicial destas pesquisas foi o de colher dados que pudessem definir o quadro local dos focos silvestres e domiciliados de $P$. megistus. Para tanto, nas localidades escolhidas foram delimitados terrenos circulares com $600 \mathrm{~m}$ de raio e cujo centro correspondeu a uma das casas locais para tanto selecionada arbitrariamente. Daí resultaram quatro áreas, assim distribuídas (Fig. 11.
Área
Localidade

$\begin{array}{ll}\text { A } & \text { Bairro da Carqueja } \\ \text { B } & \text { Bairro Jacaré } \\ \text { C } & \text { Bairro da Boiada } \\ \text { D } & \text { Bairro Monte Alto }\end{array}$

Em cada uma delas. efetuou-se o levantamento das habitações e seus anexos. estes representados por locais de animais domésticos. depósitos cohertos ("paióis") ou não. abrigos de fossas cercas e outros. Além disso. esse reconhecimento implicou procedimento análogo em relação ao amhiente extradomiciliar silvestre. incluindo todos os tipos de regetação ali encontrados.

Em etapa seguinte. levada a efeito no, período de setembro de 1971 a outubre de 1972. foram pesquisados todos os ecótopos artificiais constituidos pelas casas $t$ seus anexos. has quatro áreas. No mesmo espaço de tempo. procedeu-se ao exame 
Forattini, O. P. et al - Aspectos ecológicos da Tripanossomiase amerucana. ViII - Domiciliação de Panstrongylus megistus e sua presença extradomiciliar. Rev. Saúde públ. S. Paulo, 11:73-86, 1977.

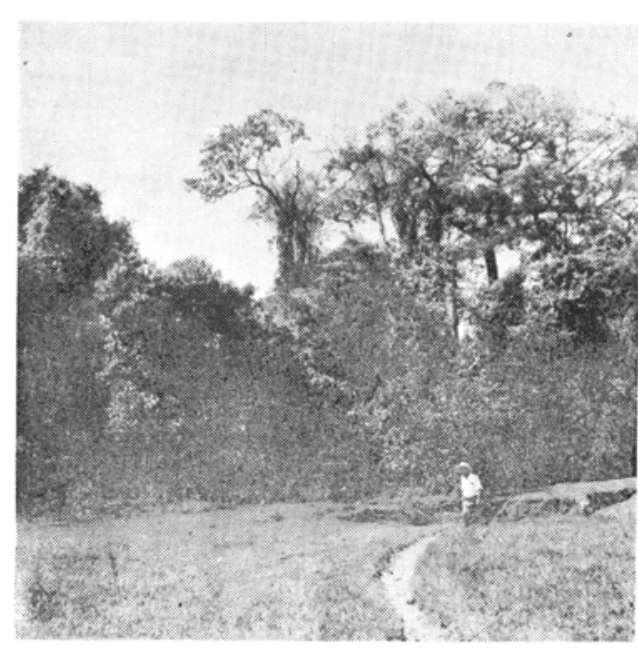

Fig. 4 - Mata residual do Bairro da Boiada.

dos possíveis ecótopos naturais em $A, B$ e C. focalizando palmeiras, árvores vivas cu secas. troncos ocados. e ninhos de animais incluindo cercas e amontoados de material distantes das hahitações. Estas pesquisas no ambiente extradomiciliar foram realizadas de maneira a resultar no deshastamento manual desses hiótopos.

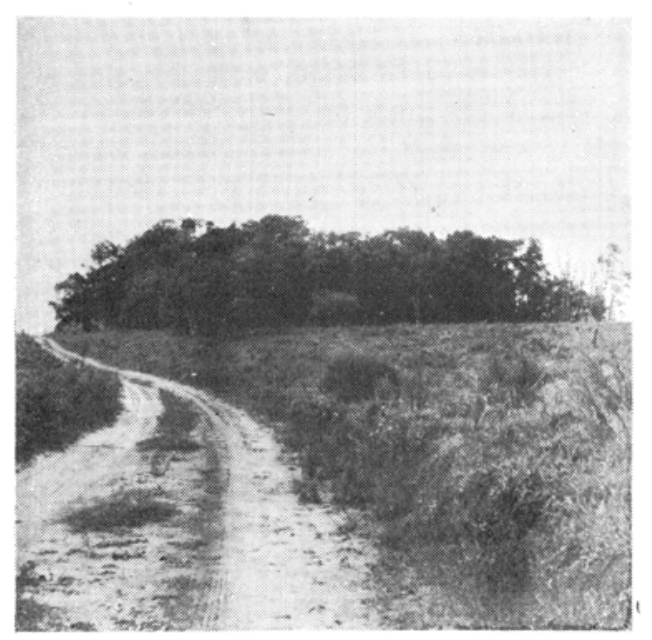

Fig. 5 - Bata residual do Bairro Monte Alto
Concomitantemente às atividades supracitadas. foram construídos galinheiros experimentais $(\mathrm{GE})$. obedecendo à mesma técnica já descrita em publicação anterior (Forattini e col.!. 1973). Para localizálos. levou-se em consideração a possível influência resultante da destruição dos ecótopos naturais por ocasião do supracitado levantamento. Além disso, pretendeu-se focalizar o papel das manchas de matas residuais e. assim. o referente aos dois tipos de ambientes. representados pelos terrenos. coberto e descoberto, em relação a esse revestimento regetal. Face a tais fatores. decidiu-se colocar essas construções. em locais onde a pesquisa de ecótopos naturais nāo fora realizada. obviando assim o possivel fator de negatividade que pudesse ser atrihuído a essa destruição. Dessa maneira os $\mathrm{GE}$ foram dispostos nos Bairros da Carqueja. Boiada e Monte Alto. em número de dois para cada localidade. Na primeira escolheu-se situação fora das áreas trabalhadas A e B e correspondente ao sopé da escarpa. entre a regetação local (Fig. 6). Outros dois foram colocados também fora da área trabalhada $C$ e o par restante foi instalado. em região onde não se procedeu à pesquisa no ambiente silvestre. e incluída no Bairro Monte Alto. Nestes últimos quatro GE. para cada área. a situação obedeceu ao critério de situar um dentro da mata residual e outro no terreno aberto e exterior à vegetação (Fig. 7, 8). Dessa maneira, e de acordo com a orientação descrita. a disposição desses seis ecótopoartificiais foi a seguinte:

GE Localização Instalação

a 1. a 2 ... Bairro da Carqueja (áreas A e B) entre a regetação do sopé da escarpa

(. 1 ..... Bairro da Boiada (área C) dentro da mata residual 
FORATTINI, O. P. et al. - Aspectos ecológicos da Tripanossomíase americana. VIII - Domiciliação de Panstrongylus megistus e sua presença extradomiciliar. Rev. Saúde públ., S. Paulo, 11:73-86, 1977.

\section{c $2 \ldots \ldots$ Bairro da Boiada (área C) fora da mata residual \\ d $1 \ldots .$. . Bairro Monte Alto (área D) dentro da mata residual}

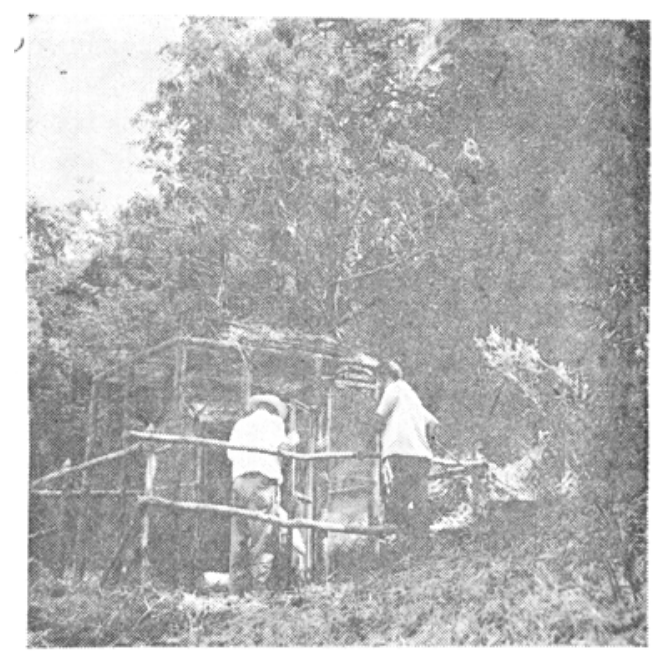

Fig 6 - Galinheiro experimental (GE) a 1 instalado no sopé da Serra da Carqueja.

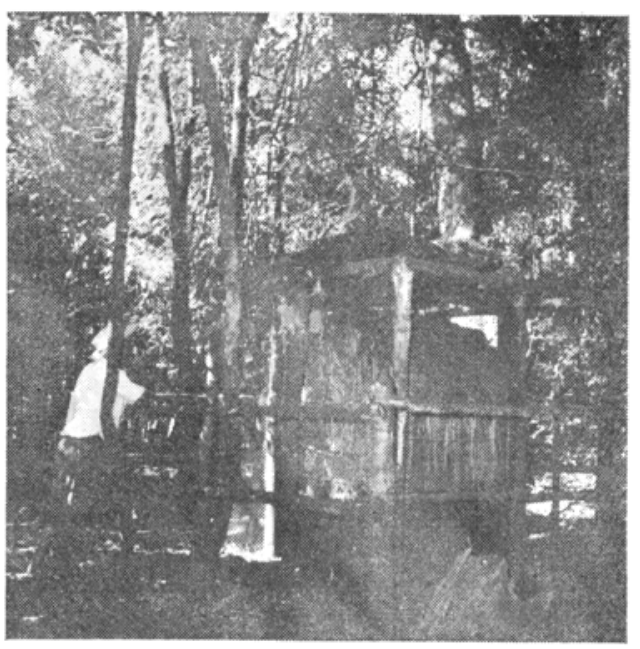

Fig. 7 - Galinheiro experimental (GE) c 1 instalado dentro da mata residual do Bairro da Boiada.

\section{d $2 \ldots$... Bairro Monte Alto (área D) fora da mata residual}

19.XI.71

A situação geográfica desses GE poderá ser apreciada no mapa da Fig. 1.

\section{RE SUI TA DOS}

Ambicnte domiciliar - os resultados dos exames das casas e seus anexos, nas várias áreas, acham-se expostos nas $\mathrm{Ta}$ belas 1 e 3 . Pode-se verificar a negatividade das habitações e a baixa positividade limitada aos anexos. Todavia devese ressaltar o relativamente pequeno número de casas examinadas e o aspecto peculiar de um desses anexos ter sido representado por depósito que servia de pernoite a pessoa moradora da localidade (Fig. 9). Ali foi encontrado o maior foco domiciliado de $P$. megistus, representado pela coleta de 16 adultos e 221 ninfas (Tabela 3). De qualquer forma, nas quatro áreas, o triatomíneo apresentou aspecto relativamente uniforme, ou seja, o de se encontrar domiciliado embora confinado ao peridomicílio.

Ambiente silvestre ou extradomiciliar - para as três áreas onde foi levada a efeito a pesquisa no ambiente extradomiciliar (A. B e C) os resultados acham-se resumidos nas Tabelas 2 e 3 . Foram encontrados 7 focos de $P$. megistus em ecótopos naturais de aspecto constantemente representado por árvores ocadas, ou seja, que apresentam o tronco escavado (Fig. 10). Desses focos, seis situavam-se dentro das matas residuais e um em espaço aberto. Este foi representado por árvore seca localizada dentro dos limites de terreno cultivado. Todos esses biótopos, constituiam-se em abrigos de animais silvestres, albergando ninhos e locais de repouso identificados pelos vestígios encontrados ou pelos próprios animais ali surpreen- 
FORATTINI, O P. et al - Aspectos ecológicos da Tripanossomíase americana. VIII - Domiciliação de Panstrongylus megistus e sua presença extradomiciliar. Rer. Saúde públ. S. Paulo, 11:73-86, 1977.

T A B E L A 1

Ǩesultados quantitativos das coletas de Panstrongylus megistus em ecótopos do ambiente domiciliar

\begin{tabular}{|c|c|c|c|c|c|c|}
\hline \multirow{2}{*}{ Área } & \multicolumn{2}{|c|}{ Casas } & \multicolumn{2}{|c|}{ Anexos } & \multicolumn{2}{|c|}{ Total } \\
\hline & $N$ & + & $\mathrm{N}$ & + & $\mathrm{N}$ & + \\
\hline A & 10 & - & 45 & 3 & 55 & 3 \\
\hline B & 4 & - & 21 & 1 & 25 & 1 \\
\hline $\mathrm{C}$ & 4 & - & 20 & - & 24 & - \\
\hline $\mathrm{D}$ & 2 & - & 12 & 1 & 14 & 1 \\
\hline Total & 20 & - & 98 & 5 & 118 & 5 \\
\hline
\end{tabular}

T A B E L A 2

Resultados quantitativos das coletas de triatomíneos em ecótopos do amb:ente silvestre

\begin{tabular}{|c|c|c|c|c|c|}
\hline \multirow{2}{*}{ Ârea } & \multicolumn{2}{|c|}{ Ecótopos } & \multicolumn{3}{|c|}{ Ecótopos positivos } \\
\hline & $\mathrm{N}$ & + & & Tipos & Triatomíneo \\
\hline A & 315 & 9 & $\begin{array}{l}1 \text { árvore } \\
8 \text { ninhos }\end{array}$ & $\begin{array}{l}\text { seca e ocada } \\
\text { de aves (*) }\end{array}$ & $\begin{array}{l}\text { Panstrongylus megistus } \\
\text { Psammolestes tertius }\end{array}$ \\
\hline $\mathrm{B}$ & 248 & - & 5 ninhos & de aves $(*)$ & Psammolestes tertius \\
\hline $\mathrm{C}$ & 427 & 6 & $\begin{array}{l}1 \text { árvore } \\
5 \text { árvores }\end{array}$ & $\begin{array}{l}\text { viva e ocada } \\
\text { secas e ocadas }\end{array}$ & $\begin{array}{l}\text { Panstrongylus megistus } \\
\text { Panstrongylus megistus }\end{array}$ \\
\hline Total & 990 & 15 & & 20 & $\begin{aligned} 7 & \text { p. P. megistus } \\
13 & \text { p. Ps. tertius }\end{aligned}$ \\
\hline
\end{tabular}

(*) Anumbius annumbi ("joão-graveto").

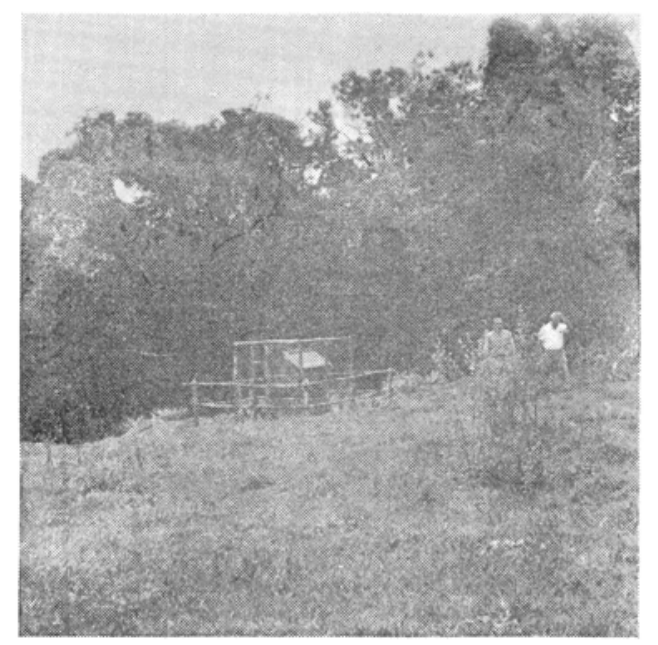

Fig. 8 - Galinheiro experimental (GE) c 2 instalado fora da mata residual do Bairro da Bojada. didos por ocasião do exame. Dessa manteira. pôde-se evidenciar a presença nesses ecótopos de gambás (Didelphis), morcegos. roedores aves.

Gulinheiros experimentais $1 G E)$ - Decorrido tempo que rariou de 13 a 16 meses de sua instalação. os seis GE foram objeto de exame em 26 e 27.III.1973. Os resultados oftidos acham se expostos na Tabela 4. Pôde-se evidenciar a colonização do triatomineo $\mathrm{x} m$ dois deles, a $I$ e c 1. tendo sido tamhém surpreendida sua passagem em outro. $d$ l. revelada pela presença de um ovo eclodido. Por tais resultados verifica-se que a instalação do $P$. megistus somente ocorreu nos ecólopos construídos dentro da regetação, seja no sopé da escarpa. suja no conjunto de matas residuais. Acresce que um dos 
FORATTINI, O. P. et al. - Aspectos ecológicos da Tripanossomiase americana. VIII - Domiciliaçāo de Panstrongylus megıstus e sua presença extradomiciliar. Rev. Saúde públ., S. Paulo, 11:73-86, 1977.

TABELA 3

Resultados quantitativos das formas de Panstrongylus megistus encontradas nos ecotopos domiciliares e silvestres

\begin{tabular}{|c|c|c|c|c|c|c|c|c|}
\hline \multirow{2}{*}{ Area } & \multicolumn{4}{|c|}{ Domiciliares } & \multicolumn{4}{|c|}{ Silvestre } \\
\hline & Tipo & NF & $A D$ & ov & Tipo & NF & $A D$ & ov \\
\hline \multirow[t]{3}{*}{$A$} & paiol & 6 & - & - & árvore seca e & - & 1 & 3 \\
\hline & abrigo de fossa & 2 & 2 & - & & & & \\
\hline & depósito (*) & 221 & 16 & ne & & & & \\
\hline B & chiqueiro & 3 & 1 & - & - & - & - & - \\
\hline \multirow[t]{2}{*}{$c$} & - & 一 & - & - & $\begin{array}{l}5 \text { arvores secas } \\
\text { e ocadas }\end{array}$ & 24 & - & 6 \\
\hline & & & & & $\begin{array}{l}\text { árvores viva e } \\
\text { ocada }\end{array}$ & 9 & - & 一 \\
\hline $\mathrm{D}$ & galinheiro & 一 & 2 & - & $(* *)$ & & & \\
\hline Total & 5 & 232 & 21 & ne & 7 & 33 & 1 & 9 \\
\hline \multicolumn{9}{|c|}{$A D$ - Adultos } \\
\hline \multicolumn{9}{|c|}{ NF - ninfas } \\
\hline \multicolumn{9}{|c|}{ ov - ovos } \\
\hline \multicolumn{9}{|c|}{ nc - não contados } \\
\hline $\begin{array}{l}(*)- \\
(* *)-\end{array}$ & $\begin{array}{l}\text { servindo de perno } \\
\text { pesquisa não rea }\end{array}$ & para & soa & $i \tan$ & da localidade. & & & \\
\hline
\end{tabular}

$G E$, o $c 2$, teve seu exame prejudicado face à colonização local de grande colônia de carrapatos Argasidae.

\section{O M E N TAR I O S}

Como se referiu a persistência de Panstrongylus megistus no ambiente domiciliar constitui fato observado há certo tempo. No caso particular da região objeto do presente estudo, tal aspecto foi assinalado desde as primeiras pesquisas de Freitas ${ }^{11}$ (1963), que atribuiu esse fenômeno, pelo menos em parte, à presença de focos extradomiciliares. Os resultados aqui relatados concordam com os desse autor. em suas linhas gerais.

Parece fora de dúvida que a população local do triatomíneo encontra-se como que assediando a casa do homem, tentando in-

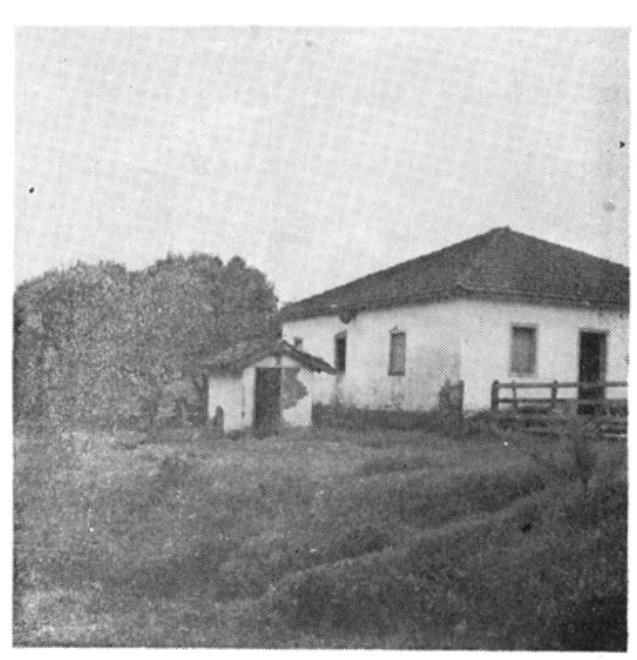

Fig. 9 - Depósito peridomiciliar no Bairro da Carqueja, encontrado infestado por $P$. megis. tus. Esse anexo, ao lado da casa, servia de pernoite a pessoa habitante da localidade. 
FORATTINI, O. P. et al. - Aspectos ecológicos da Tripanossomiase americana. VIII - Domiciliação de Panstrongylus megistus e sua presença extradomiciliar. Rev. Saúde públ., S. Paulo, 11:73-86, 1977.

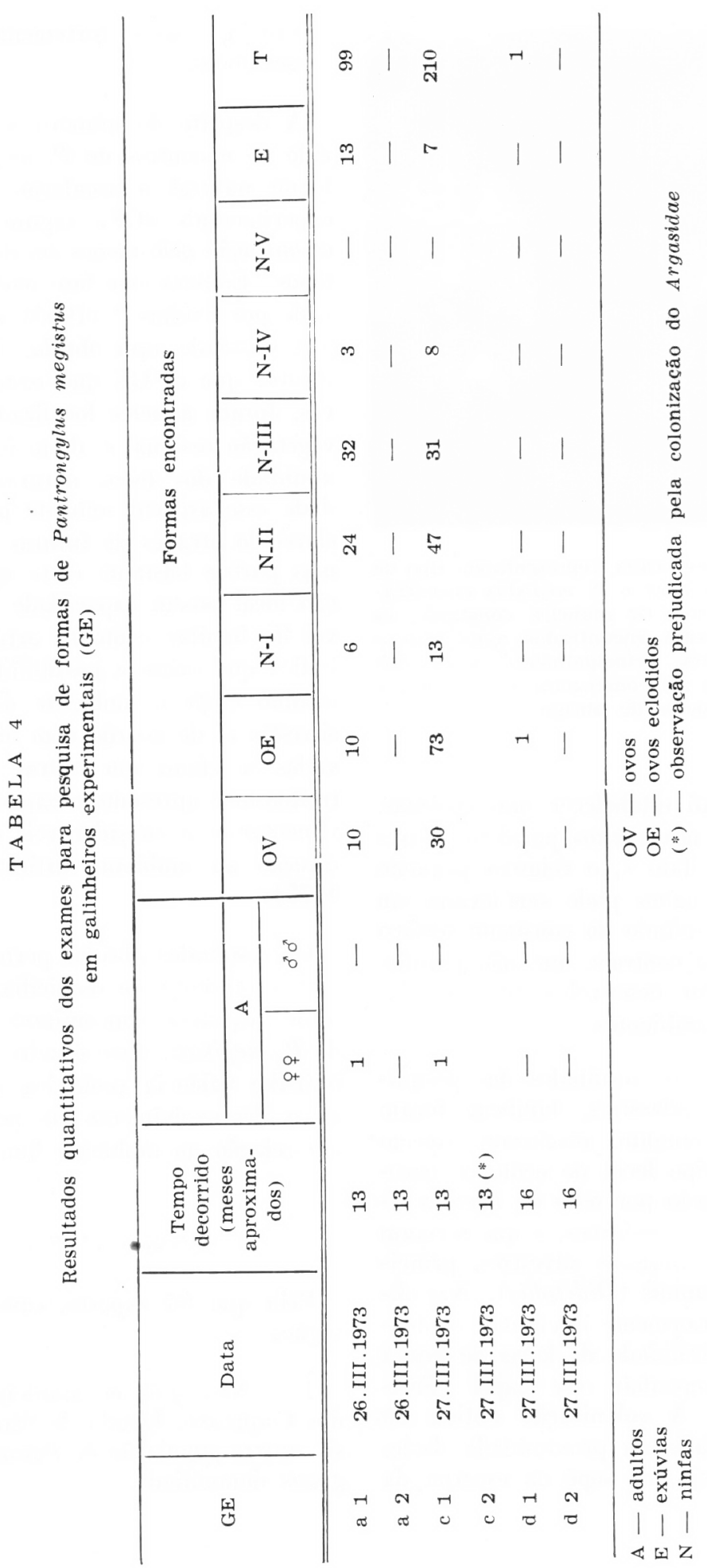


FORATTINI, O. P. et al. - Aspectos ecológicos da Tripanossomíase americana. VIII - Domiciliação de Panstrongylus megistus e sua presenca extradomicillar. Rev. Saúde públ. S. Paulo, 11:73-86, 1977.

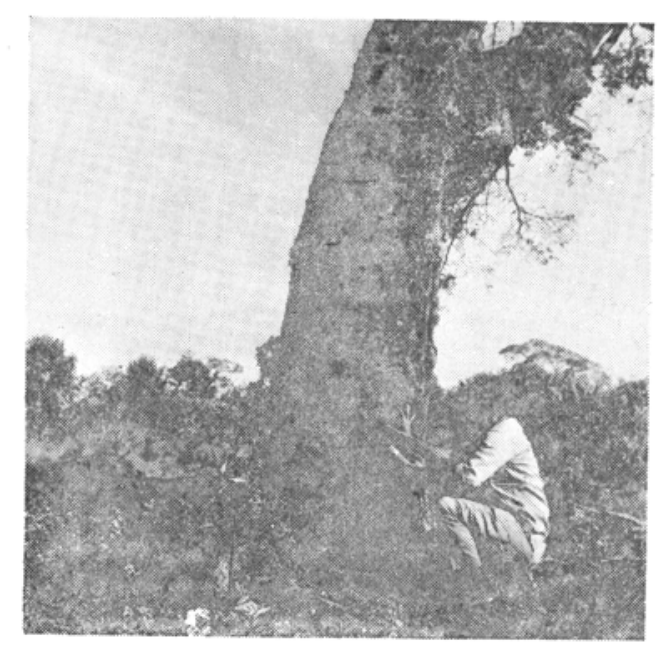

Fig. 10 - Árvore ocada, representando tipo de ecótopo natural para o $P$. megistus encontrado na localidade. De maneira constante, os triatomíneos foram encontrados associados a animais silvestres, principaimente marsupiais (Didelphis) que ali construiam seus ninhos e locais de abrigo.

vadi-la para ali estabelecer suas colônias. Sua presença nos anexos peridomiciliares evidencia esse fato $e$, o relativo pequeno número de achados pode ser levado em conta como resultado do constante serviço de vigilância e controle, que não permite ao inseto maior desenvolvimento populacional nesses ambientes.

Por sua vez, os resultados das pesquisas de focos silvestres, também foram escassos. No entanto, revelaram aspecto constante no tipo local de ecótopos naturais, representado por ocos de árvores situadas nas matas residuais, e que serviam de abrigo a mamíferos silvestres, principalmente marsupiais (Didelphis). Nas observaçōes anteriormente já citadas, evidenciou-se a possibilidade de locas de pedra virem a desempenhar esse papel (Frei$\left.\operatorname{tas}^{10}, 1963\right)$. A colonização obtida no GE $a$ 1, instalado na proximidade desses biótopos, ou seja, no sopé da escarpa da
Carqueja, sugere fortemente a presença desses focos.

A despeito do número um tanto reduzido de encontros do $P$. megistus no ambiente natural, à instalação de galinheiros experimentais (GE) seguiu-se apreciável colonização pelo menos em dois desses ecótopos. Embora esse fato tenha sido observado por Freitas ${ }^{10}$ (1963) não o foi com a intensidade aqui obtida. Pode-se argumentar que os GE que resultaram positivos, foram aqueles localizados dentro da vegetação residual e, desta forma, em proximidade dos focos naturais. $\mathrm{Na}$ realidade esse aspecto somente poderá ser esclarecido através de futuras investigações, mas parece bastante claro que a população local possui capacidade não desprezível de habitar ecótopos artificiais. Tudo indica que existe a possibilidade de intercâmbio entre o ambiente domiciliar e o silvestre e, de acordo com observações levadas a efeito em outras regióes, esse triatomíneo apresenta a capacidade de movimentar-se a consideráveis distâncias em direção ao ambiente artificial (Miles ${ }^{11}$, 1975).

Os resultados obtidos permitem evidenciar a presença de domiciliação e de hábitos silvestres concomitantes, por parte do $P$. megistus. Esse quadro permite atribuir-lhe valência ecológica suficiente para o desenvolvimento de poder invasivo em relação ao ambiente humano.

\section{CONCLUSOES}

Pelo que foi exposto, conclui-se o que segue:

1 - Na região do município de Cássia dos Coqueiros, Estado de São Paulo, Brasil, ocorre população de Panstrongylus megistus domiciliada. 
FORATTINI, O. P. et al. - Aspectos ecológicos da Tripanossomiase americana. VIII - Domiciliação de Panstrongylus megistus e sua presença extradomiciliz.r. Rev. Saúde públ., S. Paulo, 11:73-86, 1977.

2 - Nesse particular situa-se, pois, na área de distribuição geográfica onde esse triatomíneo desempenha papel de transmissor da tripanossomíase americana.

3 - Ao lado da domiciliação, a população local do inseto encontra-se habitando o ambiente extradomiciliar, representado principalmente pelos aglomerados de matas residuais.
4 - A população silvestre apresenta capacidade evidente de ocupar ecótopos artificiais, demonstrada pela franca colonização de galinheiros experimentais (GE).

5 - Na dependência de sua capacidade de dispersão e mobilidade, o ambiente domiciliar estará sujeito à invasão por parte do triatomíneo, a partir desses focos situados nas matas residuais.

RSPU-B $/ 340$

Forattini, O. P. et al. [Ecological aspects of South American Trypanosomiasis. VIII - Local domiciled and wild pattern of Panstrongylus megistus.] Rev. Saúde públ., S. Paulo, 11:73-86, 1977.

ABSTRACTS: Local pattern of domiciled and wild distribution of Panstrongylus megistus was observed through artificial and natural ecotopes investigation. The bug was found inhabiting periodomestic dwellings and hollow trees in the sylvatic environment serving as shelters for wild animals. This was mainly represented by spots of remaining forests. Colonization of experimental chicken houses was obtained suggesting that interchange occurs between natural and artificial ecotopes. So it seems suitable to atribute high ecological valence to this bug population.

Uniterms: Trypanosomiasis, South American. Pantrongylus megistus. Triatomids bugs, domiciliarity. Medical ecology.

\section{REFERENCIAS BIBLIOGRAFICAS}

1. AB'SABER, A. - O Planalto de Franca: estudos básicos para planejamento regional. São Paulo, Instituto de Geografia da USP, 1975. (Série Geografia e Planejamento, 15).

2. ARAGão, M.B. - Aspectos climáticos da doença de chagas. II - Area de ocorrência do Panstrongylus megistus (Burmeister, 1835), Rev. bras. Malar., 13:171-93, 1961.

3. BARRETTO, M.P. - Aspectos da epidemiologia da tripanossomose americana, infecção com focos naturais, com especial referència à regiāo nordeste do Estado de São Paulo. Ribeirāo Preto, 1966. [Tese - Faculdade de Farmácia e Odontologia da USP].
4. DIAS, J.C.P. - Reinfestacão do município de Bambui por triatomineos transmissores da doenca de Chagas. Mem. Inst. Oswaldo Cruz, 63:107-19, 1965.

5. DIAS, J.C.P. - Reinfestação do município de Bambuí por triatomineos transmissores da doenca de Chagas (2.a nota). Mem. Inst. Oswaldo стиz, 66:197-208, 1968.

6. FORAtTini, O.P. et al. - Aspectos ecológicos da tripanossomose ame. ricana. I - Observações sobre Panstrongylus megistus e suas relaçōes com focos naturais da infeccão, em área urbana da cidade de São Paulo, Brasil. Rev. Saúde públ., S. Paulo, 4:19-30, 1970. 
FORATTINI, O. P. et al. - Aspectos ecológicosda Tripanossomíase americana. VIII - Domiciliação de Panstrongylus megistus e sua presença extradomiciliar. Rev. Saúde pübl., S. Paulo, 11:73-86, 1977.

7. FORATTINI, O.P. - Entomogeografia médica do Brasil. In: Lacaz, C.S. et al. ed. - Introdução à geografia médica do Brasil, São Paulo, Ed. Edgar Blücher/USP, 1972. p. 191212 .

8. FORATTINI, O.P. - Effects of control measures on vector populations dynamics. In: International Symposium on New Approaches in American Trypanosomiasis Research. Belo Horizonte, 1975. Proceedings. Washington, D.C., Pan-American Health Organization, 1976. p. 21.3. (Scientific Publication, 318).

9. FORATTINI, O.P. et al. - Aspectos ecológicos da tripanossomose americana. V - Observações sobre colonização espontânea de triatomineos silvestres em ecótopos artificiais, com especial referêncla ao Triatoma sordida. Rev. Saúde públ., S. Paulo. 7:219-39, 1973.

10. FREITAS, J.L.P. de - Importância do expurgo seletivo dos domicilios e anexos para a profilaxia da moléstia de Chagas pelo combate aos triatomineos. Arq. Hig., S. Paulo, 28: 217-72, 1963.

11. MILES, M.A. - Distribution and importance of triatominae as vector of $T$. cruzi. In: International Symposium on New Approaches in Ameri- (an Trypanosomiasis Research. Belo Horizonte, 1975. Proceedings. Washington, D.C., Pan-American Health Organization, 1976. p. 48-56. (Scientific Publication, 318).

12. MONTEIRO, C.A. de F. - A dinâmica climática e as chuvas no Estado de São Paulo. São Paulo, Instituto de Geografia da USP, 1973.

13. PESSÓA, S.B. - Domiciliação dos trıtomineos e epidemiologia da doença de Chagas. Arq. Hig., S. Paulo, 27: 161- $71,1962$.

14. ROCHA E SILVA, E.O. da et aI. Suspensão do rociado no combate ao Triatoma infestans em áreas do Estado de São Paulo, Brasil. Rev. Saú. de públ., S. Paulo, 3:173-81, 1969.

15. SETZER, J. - Atlas climático e ecológico do Estado de São Paulo. São Paulo. Comissão Interestadual da Bacia Paraná-Uruguai e Centrais Elétricas de São Paulo, 1966.

16. TROPPMAIR, H. - Regiões ecológicas do Estado de São Paulo. São Paulo, Instituto de Geografia da USP, 1975. (Série Biogeografia, 10).

Recebido para publicação em 08/09/1976 Aprovado para publicação em 10/09/1976 